\title{
PREDICTION OF THE RISK OF DEVELOPING TYPE 2 DIABETES MELLITUS USING BODY MASS INDEX IN ADOLESCENTS
}

\author{
Shanthi' ${ }^{1}$ Manjunathaㄹ, Sagar Bharamakkanavar ${ }^{3}$ \\ ${ }^{1}$ Senior Resident, Department of Paediatrics, Aster CMI Hospital, Bangalore, Karnataka, India. \\ ${ }^{2}$ Associate Professor, Department of Paediatrics, Cheluvamba Hospital MMC\&RI, Mysore, Karnataka, India. \\ ${ }^{3}$ Resident, Department of Paediatrics, Cheluvamba Hospital MMC\&RI, Mysore, Karnataka, India.
}

\begin{abstract}
BACKGROUND

Overweight and obesity are recognized as an escalating epidemic affecting both developed and developing countries. Body Mass Index (BMI) is promulgated by WHO as the most useful epidemiological measure of obesity. Obesity is one of the most important modifiable risk factors in pathogenesis of type 2 diabetes mellitus. Studies have indicated that Indians are highly susceptible to diabetes even with modest overweight, central obesity and physical inactivity. The objectives of this study were- 1 . to determine the relation between body mass index and fasting blood sugar 2. to determine the factors influencing childhood obesity and type 2 diabetes.
\end{abstract}

\section{MATERIALS AND METHODS}

After obtaining consent from the school authorities and parents, details of the children were collected. Weight, height and fasting blood sugar of the children were measured. Body Mass Index was calculated. The data was analysed statistically.

\section{RESULTS}

The prevalence of overweight was $14.8 \%$ and obesity was $9.0 \%$. There is a positive correlation between Body Mass Index and Fasting Blood Sugar with a r value of 0.826 and a p value of 0.0001 . Socioeconomic status and TV watching time have a positive influence on Body Mass Index. Family history of type 2 Diabetes Mellitus has a positive correlation with Body Mass Index and Fasting Blood Sugar.

\section{CONCLUSION}

The prevalence of overweight and obesity among adolescent children is on a raising trend. There is a positive correlation between fasting blood sugar and Body Mass Index. Socioeconomic status and TV watching time have a positive influence on Body Mass Index. Family history of type 2 Diabetes Mellitus has a positive correlation with Body Mass Index and Fasting Blood Sugar.

\section{KEY WORDS}

Body Mass Index; Fasting Blood Sugar; Obesity; Diabetes Mellitus

HOW TO CITE THIS ARTICLE: Shanthi, Manjunatha, Bharamakkanavar S. Prediction of the risk of developing type 2 diabetes mellitus using body mass index in adolescents. J. Evolution Med. Dent. Sci. 2019;8(11):800-803, DOI: 10.14260/jemds/2019/176

\section{BACKGROUND}

Obesity is one of the most complex and poorly understood clinical syndromes affecting children and adults throughout the world. ${ }^{1}$ Overweight and obesity are recognized as an escalating epidemic affecting both developed and developing countries. World Health Organization (WHO) has declared obesity as a disease of pandemic significance. ${ }^{2}$

Worldwide obesity has more than doubled since $1980 .^{3}$ Overweight and obesity have reached a peak of epidemic in developed countries and now begins to decline but at present it is rapidly increasing in many middle-income and lowincome countries. ${ }^{4,5}$ Hence the developing countries face the dual problem of newly increasing obesity and previously existing malnourishment.

'Financial or Other Competing Interest': None.

Submission 23-01-2019, Peer Review 28-02-2019,

Acceptance 06-03-2019, Published 18-03-2019.

Corresponding Author:

Dr. Manjunatha,

Associate Professor,

Department of Paediatrics,

Cheluvambha Hospital MMC\&RI,

Mysore-570001, Karnataka, India.

E-mail: manjunatha0505@gmail.com

DOI: $10.14260 /$ jemds $/ 2019 / 176$

\section{(c) (i) $(9)$}

With a rapid demographic and socioeconomic transition, India is becoming the epicenter of epidemics of both adult and childhood obesity, especially in urban populations. Although the age-standardized rates are low, in absolute terms India is the country with the third-highest level of obesity in the world. Over the years, epidemiological studies have reported a consistent increase in the prevalence of childhood overweight and obesity in the subcontinent. ${ }^{6}$

Body Mass Index (BMI) is promulgated by WHO as the most useful epidemiological measure of obesity. ${ }^{7}$ BMI (Weight in kilograms divided by the square of the height in meters) serves as a useful surrogate, is easily obtained in clinic settings and correlates strongly with body fat and risks of co-morbidities in obese subjects. ${ }^{8}$

The risk factors implicated in the development of overweight and obesity are genetic factors, environmental factors and perinatal factors. The most important and modifiable factors being the environmental factors like physical inactivity, television viewing, consumption of junk food etc.

Obesity is associated with comorbidities like type 2 diabetes, hypertension, dyslipidaemia, cardiovascular disorders, polycystic ovaries, etc., Type 2 diabetes mellitus is a major complication of childhood obesity and it can cause morbidity and mortality. 
Studies related to correlation between Body Mass Index and Fasting Blood Sugar levels are available in adults. But there is a relative paucity of data about the same in adolescent children. Clarification of this issue in Indian adolescent children may help by implementation of more effective public health policies and also clinical efforts can be aimed at primary prevention of type 2 diabetes mellitus through weight control.

Hence, the present study is undertaken to estimate body mass index and fasting blood sugar of adolescent school children of Mysore, to determine the correlation between the two parameters and to predict the risk of these children developing type 2 diabetes mellitus.

\section{MATERIALS AND METHODS}

We hypothesize on the basis of previous studies that the children with higher body mass index will have higher FBS levels and higher BMI predicts a higher risk of developing type 2 diabetes mellitus.

\section{Sample Size}

Sample size was taken based on the convenience of the study

\section{Source of Data}

Higher primary and high school children of Mysore from 10 to 16 years of age.

\section{Sampling Method}

Stratified random sampling.

\section{Type of Study}

Cross sectional study.

\section{Inclusion Criteria}

Higher primary and High school children from Mysore between 10-16 years of age.

\section{Exclusion Criteria}

a. Children with diagnosed diabetes mellitus type 1 or 2 .

b. Children with diseases like Cushing's syndrome, renal disorders which can also lead to diabetes mellitus.

c. Children who are on long term medications with steroids (Inhaled or oral) and anti-epileptic drugs.

\section{Ethical Approval}

The study was approved by the Institutional Ethics Committee.

After obtaining Institutional Ethical Committee clearance and permission of the school authorities of children, proforma to collect basic information of the children along with family history and consent forms was given to the children, one day prior to examining them. They were asked to take it home and get it signed by their parents. They were requested to come to school on the day of examination without having breakfast i.e., after fasting for 8 hours. Children were examined; height and weight were measured. Using the standard formula, body mass index was calculated. They were classified as normal, overweight and obese based on WHO charts. All the children were subjected to a fasting blood glucose monitoring using glucometer, by pricking the fingertip with lancet and capillary blood sample was used. Body mass index and fasting blood glucose levels were correlated statistically.

\section{Statistical Methods Used}

Descriptive statistics -study mean, standard deviation, frequency and percentage.

\section{Inferential}

Crosstabs (Crame's V test) one-way ANOVA.

\section{RESULTS}

Out of the 50 underweight children, 47(94\%) had a FBS $\leq 85$ $\mathrm{mg} / \mathrm{dl}$. Of the 255 children with normal BMI, 140(54.9\%) had a FBS $\leq 85 \mathrm{mg} / \mathrm{dl}, 100(39.2 \%)$ had a FBS $86-90 \mathrm{mg} / \mathrm{dl}$. Of the 59 overweight children, $48(81.3 \%)$ had a FBS $91-95 \mathrm{mg} / \mathrm{dl}$ Of the 36 obese children in the study group, 33(91.6\%) had a FBS $\geq 96 \mathrm{mg} / \mathrm{dl}$.

\begin{tabular}{|c|c|c|c|c|c|}
\hline $\begin{array}{c}\text { FBS } \\
\text { (mg/dl) }\end{array}$ & $\begin{array}{c}\text { Under- } \\
\text { weight }\end{array}$ & Normal & $\begin{array}{c}\text { Over- } \\
\text { Weight }\end{array}$ & Obesity & Total \\
\hline$\leq 85$ & $\begin{array}{c}47 \\
(94.0 \%)\end{array}$ & $\begin{array}{c}140 \\
(54.9 \%)\end{array}$ & $\begin{array}{c}5 \\
(8.5 \%)\end{array}$ & $\begin{array}{c}0 \\
(0 \%)\end{array}$ & $\begin{array}{c}192 \\
(48.0 \%)\end{array}$ \\
\hline $86-90$ & $\begin{array}{c}2 \\
(4.0 \%)\end{array}$ & $\begin{array}{c}100 \\
(39.2 \%)\end{array}$ & $\begin{array}{c}5 \\
(8.5 \%)\end{array}$ & $1(2.8 \%)$ & $\begin{array}{c}108 \\
(27.0 \%)\end{array}$ \\
\hline $91-95$ & $\begin{array}{c}1 \\
(2.0 \%)\end{array}$ & $10(3.9 \%)$ & $\begin{array}{c}48 \\
(81.4 \%)\end{array}$ & $2(5.6 \%)$ & $\begin{array}{c}61 \\
(15.2 \%)\end{array}$ \\
\hline$\geq 96$ & 0 & 5 & 1 & 33 & 39 \\
$(0 \%)$ & $(2.0 \%)$ & $(1.7 \%)$ & $(91.7 \%)$ & $(9.8 \%)$ \\
\hline Total & $\mathbf{5 0}$ & $\mathbf{2 5 5}$ & $\mathbf{5 9}$ & $\mathbf{3 6}$ & $\mathbf{4 0 0}$ \\
\hline Table 1. Correlation Between FBS and BMI in The Study \\
Population
\end{tabular}

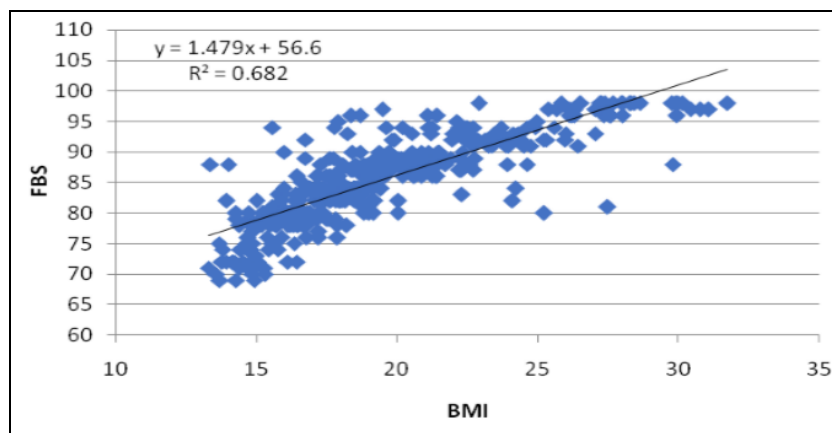

Figure 1. Correlation Between FBS and BMI in The Study Population

Equation: $\mathrm{FBS}=1.479 * \mathrm{BMI}+56.6$

Pearson's correlation $r=0.826, p=0.0001$.

Correlation is significant at the 0.01 level (2-tailed). FBS correlated with BMI linearly and positively.

\section{DISCUSSION}

Overweight and obesity are recognized as an escalating epidemic affecting both developed and developing countries. Obesity is associated with comorbidities like type $2 \mathrm{DM}$, hypertension, dyslipidaemia, cardiovascular disorders, polycystic ovaries. Type 2 diabetes mellitus is a major complication of childhood obesity and it can cause morbidity and mortality. In this study, we aim to determine the relation between body mass index and fasting blood sugar. We also 
studied the factors influencing childhood obesity and type 2 diabetes.

In our study 400 adolescent school children from Mysore were studied. After obtaining informed consent demographic details of the children were collected using a proforma, weight, height and fasting blood glucose was measured. Results were analysed.

In a study conducted by M Shashidhar Kotian et $\mathrm{al}^{9}$ in the year 2010, the prevalence of overweight was $9.9 \%$ and obesity was $4.8 \%$. In a study conducted by Premnath et al 10 in the year 2008, the prevalence of overweight was $8.5 \%$ and obesity was $3.4 \%$ but this study included children from 5- 16 years of age. We studied 400 adolescent school children and the prevalence of overweight was $14.8 \%$ and prevalence of obesity was $9 \%$. This may indicate a raising trend of prevalence of overweight and obesity in adolescent children.

Aqeela Hamad et al,11 in their study found a significant correlation between BMI and FBS. The Pearson's correlation $r$ was 0.66 and $\mathrm{p}$ was $<0.0001$ (Correlation was considered as significant at $\mathrm{P}<0.05)$. Similarly, in the present study, a significant correlation was found between BMI and FBS. The Pearson's correlation $r$ was 0.6826 and $p$ was $<0.0001$ (Correlation was considered as significant at $\mathrm{p}<0.01$ ).

In a study conducted by Aqeela Hamad et al, ${ }^{11}$ the FBS values have an increasing trend as the BMI increases. The average FBS of students with a normal BMI was $88 \mathrm{mg} / \mathrm{dl}$, overweight students was $95 \mathrm{mg} / \mathrm{dl}$ and obese students was $106 \mathrm{mg} / \mathrm{dl}$. Similarly, in the present study, the average FBS values have an increasing trend as BMI increases. The average FBS of children with normal BMI is $84.63 \mathrm{mg} / \mathrm{dl}$, overweight children was $91.71 \mathrm{mg} / \mathrm{dl}$ and obese children was $96.88 \mathrm{mg} / \mathrm{dl}$.

In a study conducted by $\mathrm{M}$ Shashidhar Kotian et $\mathrm{al}^{9}$ in the year 2010, the prevalence of overweight and obesity varied among the different socioeconomic groups. It was $16.2 \%$ and $13.2 \%$ in children belonging to class I SES, $10.6 \%$ and $7.1 \%$ in children belonging to class II SES, $8.6 \%$ and $3.7 \%$ in children belonging to class III SES, $10.5 \%$ and $2.0 \%$ in children belonging to class IV SES. Similarly, a study conducted by Shabana Tharkar et al12 in the year 2009, also showed that prevalence of overweight and obesity was higher in adolescents belonging to upper SES (Overweight 7.1\% and obesity $2.4 \%$ ) compared to children belonging to lower SES (Overweight $17.7 \%$ and obesity 9.8\%). Similarly, in the present study the prevalence of overweight and obesity was higher among adolescents of upper SES compared to lower SES. It was $33.3 \%$ and $20.8 \%$ in children belonging to class I SES, $23.7 \%$ and $13.2 \%$ in children belonging to class II SES, $10.1 \%$ and $6.6 \%$ in children belonging to class III SES, $4.1 \%$ and $2.0 \%$ in children belonging to class IV SES.

In a study conducted by M Shashidhar Kotian et $\mathrm{al}^{9}$ in the year 2010, the prevalence of overweight and obesity varied with the duration of television watching. It was $5.3 \%$ and $0.9 \%$ in children who watched TV for $<2$ hours, $12.1 \%$ and $5.7 \%$ in children who watched TV for $2-4$ hours and $19.5 \%$ and $15 \%$ in children who watched TV for $>4$ hours. In a study conducted by Anjana Niranjan et $\mathrm{al}^{4}$ in the year 2016 concluded that prevalence of overweight and obesity increased as the TV/ computer watching time increased. Similarly, in the present study the prevalence of overweight and obesity was higher among children who watched TV for longer duration. It was $10.1 \%$ and $6.3 \%$ in children who watched TV for $<2$ hours, $20.5 \%$ and $12.5 \%$ in children who watched TV for $2-4$ hours and $31.5 \%$ and $18.2 \%$ in children who watched TV for $>4$ hours.

In a study conducted by Aqeela Hamad et al, 11 the FBS values were higher in students with a positive family history of diabetes. The average FBS \pm SD of students with a family history of DM was $101.0 \pm 6.1 \mathrm{mg} / \mathrm{dl}$ and of students with a negative family history was $90.4 \pm 6.3 \mathrm{mg} / \mathrm{dl}$. Similarly, in the present study, the average FBS is higher in children with a positive history of DM. The average FBS \pm SD of children with a family history of DM was $89.85 \pm 6.81 \mathrm{mg} / \mathrm{dl}$ and of students with a negative family history was $83.06 \pm 5.98$ $\mathrm{mg} / \mathrm{dl}$.

In a study conducted by Aqeela Hamad et al, 11 the BMI values were higher in students with a positive family history of diabetes. The average BMI \pm SD of students with a family history of DM was $28.3 \pm 2.7 \mathrm{~kg} / \mathrm{m}^{2}$ and of students with a negative family history was $25.0 \pm 1.7 \mathrm{~kg} / \mathrm{m}^{2}$. Similarly, in the present study, the average BMI is higher in children with a positive history of DM. The average BMI \pm SD of children with a family history of DM was $22.26 \pm 4.44 \mathrm{~kg} / \mathrm{m}^{2}$ and of students with a negative family history was $18.02 \pm 2.61$ $\mathrm{Kg} / \mathrm{m}^{2}$.

\section{CONCLUSION}

The prevalence of overweight and obesity among adolescent children is on the raise. There is a positive correlation between fasting blood sugar and Body Mass Index. Socioeconomic Status and TV watching time have positive influence on Body Mass Index. Family history of type 2 Diabetes Mellitus has a positive correlation with Body Mass Index and Fasting Blood Sugar.

Children should be routinely screened for obesity in schools using standard BMI charts and overweight and obese children should be identified and intervened early. In children with obesity and in those with a positive family history of diabetes, FBS monitoring should be done at suitable intervals. Children should be encouraged to adopt a healthy lifestyle. Time spent in sedentary activities like TV watching should be reduced.

\section{REFERENCES}

[1] Alemzadeh R, Rising R, Lifshitz F. Obesity in Children. In: Lifshitz F, edr. Pediatric Endocrinology. 5th edn. New York: Informa Healthcare 2007.

[2] World Health Organization. Obesity epidemic puts millions at risk from related diseases. Isr J Med Sci 1997;33(10):706.

[3] World Health Organization (WHO). Fact sheets. (Aaccessed on August 22, 2017). http://www.who.int/end-childhood-obesity/facts/en/

[4] Niranjan A, Kumar M, Adhikari P, et al. Prevalence and determinants of overweight and obesity among undergraduate medical students of Shyam Shah Medical College, Rewa. Int J Med Sci \& Public Health 2016;5(11):2410-5.

[5] Chopra M, Galbraith S, Darnton-Hill I. A global response to a global problem: the epidemic of over nutrition. Bull World Health Organ 2002;80(12):9528. 
[6] Praveen PA, Tandon N. Childhood obesity and type 2 diabetes in India. WHO South-East Asia J Public Health 2016;5(1):17-21.

[7] Guilbert JJ. The World Health Report 2002 - reducing risks, promoting healthy life. Educ Health (Abingdon) 2003;16(2):230.

[8] Freemark M. Childhood Obesity. In: Brook C, Clayton P, Brown R, eds. Brook's Clinical pediatric endocrinology. $6^{\text {th }}$ edn. West Sussex: Wiley-Blackwell Publications 2009.

[9] Kotian MS, Kumar GS, Kotian SS. Prevalence and determinants of overweight and obesity among adolescent school children of South Karnataka, India. Indian J Community Med 2010;35(1):176-8.
[10] Premnath M, Basavanagowdappa H, Shekhar MA, et al. Mysore childhood obesity study. Indian Pediatr 2010;47(2):171-3.

[11] Hamad A, Hasan S, Javaid H. Assessment of fasting blood glucose levels and body mass index of female students of private medical college. J Coll Physicians Surg Pak 2013;12(9):545-50.

[12] Tharkar S, Viswanathan V. Impact of socioeconomic status on prevalence of overweight and obesity among children and adolescents in Urban India. The Open Obesity Journal 2009;1:9-14. 